\author{
International \\ Journal of Thysical DOI : 10.15740/HAS/IJPE/10.1and2/1-6 \\ e ISSN-0976-7924 Visit us : www.researchjournal.co.in \\ Research Paper
}

Volume 10 | Issue $1 \& 2$ | April \& October, 2017 | 1-6

\title{
Physical activity patterns of college students in Kerala
}

\section{T.I. MANOJ AND K.R. MOHAN AJITH ${ }^{1}$}

Received : 26.06.2017; Revised : 11.09.2017; Accepted : 21.09 .2017

Members of the Research Forum Associated Authors:

${ }^{1}$ Cochin University of Science and Technology, KOCHI (KERALA) INDIA

Author for correspondence :

\section{T. I. MANOJ}

Kerala Agricultural University, THRISSUR (KERALA) INDIA

\section{-ABSTRACT}

This study examines physical activity (PA) patterns in the context of international physical activity questionnaire (IPAQ) short form, which include 27 questions used for the study of undergraduate students in Kerala State, India. The sample represent proportionately the various districts of Kerala state with 1096 male (mean age $=19.44$ years) and 1841 female (mean age $=19.35$ years) in the year 2015. These following values used for the analysis of IPAQ data: Walking $=3.3$ METs, Moderate PA =4.0 METs and Vigorous PA $=8.0$ METs. The results indicate that 30.02 per cent of male and 36.5 per cent of female students found "inactive" with MET/week score below 600. At same time 57.76 per cent $(n=633)$ and 48.67 per cent $(n=896)$ male and female found in "minimally active" group, respectively with MET/week score between 600 to 1499. Only 12, 23 per cent $(n=134)$ male and 14.83 per cent $(n=273)$ found belonging to HEPA (Health-enhancing physical activity) category with MET score above 1500/ week. There is no significant difference found between genders at the same time category wise difference were found significant. The average of inactive group was MET /week was 116.49, minimally active with 995.58 MET's week and HEPA group showed PA equalling to $2148.68 \mathrm{MET} /$ week. More important, health and physical education professionals in higher education have not been able to effectively increase students' PA behaviours. Interventions to promote students' PA are still at an early stage and have only produced moderate effects. The data from the study suggest more effective interventions should be implemented to promote PA among college students.

- KEY WORDS : Physical activity patterns, IPAQ

- HOW TO CITE THIS PAPER : Manoj, T.I. and Ajith, K.R. Mohan (2017). Physical activity patterns of college students in Kerala. Internat. J. Phy. Edu., 10 (1\&2) : 1-6, DOI : 10.15740/HAS/IJPE/10.1and2/16. 